\title{
Questioning public art
}

\author{
M. Mustafa, M. Begum, A. Backer \& J. Dollah \\ School of the Arts, Universiti Sains, Malaysia
}

\begin{abstract}
Public art in Malaysia has received a mixed reception because of the confusion over its multi-faceted role and aspects of the practice. This confusion is exacerbated by the fact that public art itself is a new term in the Malaysian art scene. It is sometimes seen as a manifestation based on political and cultural aspirations that intersect with the city's beautification efforts which celebrate perfection based on wished for imagery. Fundamentally, this paper focuses on the role of public art which draw together artists, theorists, curators and arts administrators whose work engages with issues relevant to social and cultural life.

Keywords: public art, role, identity, Design Urban Guideline (DUD), Putrajaya, Malaysia, Modern Islamic concept, 'Garden City concept'.
\end{abstract}

\section{Introduction}

The study of public art in Malaysia is relatively new. Nevertheless, this study seeks to give an insight into the various roles of public art especially to the creation and development of Malaysia's administrative city - Putrajaya, conceptually and aesthetically. The methodology employed in the analysis of the mapping of the city is based on two main factors; firstly, the Design Urban Guideline and secondly, the Intelligent Garden City concept as the existing theoretical framework. Public art in Malaysia is believed to be developed to commemorate an exercise in national celebration where the core framework was designed with utopian ideals in mind. The new administrative city like the Putrajaya for example, uses public art as part its core design. Putrajaya has a majestic axis, monumental building arrangements, and ornamental and ecological environmental displays. According to the Director of the City Planning Unit of Putrajaya Corporation, Jebasingam Issace John [1] who states, 'The creation of a new Federal Government Administrative Centre at Putrajaya 
marks a new chapter in the development history of modern Malaysia... and provide a golden opportunity for the city planners to embark on a new endeavour in the planning of a new administrative centre. It is also a challenge to the planners to be innovative in planning a city to represent Malaysian values and culture'. City planners have been quick to take the cue by making "quality urban living" the basic objective for planning of major cities within the fourteen states in Malaysia. Putrajaya for example, are such city which is strategically located in the heart of the Multimedia super corridor (MSC Malaysia), a growth corridor created to spearhead the nation's development and transforming Malaysia into a 'Knowledge-based Economy and Society' as envisaged in the Vision 2020.

King [2] suggests, a more in-depth examination of public art development within major cities in Malaysia reveals ambiguities and tensions: between legislature and bureaucracy; between national integrity and global ambition; between rival views of nature and in its adopted imagery or styling; between actual and wished-for origins, and a vision of a radically different future. This development of a well-organised city is a utopian ideal as Jameson [3] notes:

'We have come laboriously to the conclusion that all ostensible Utopian content was ideological, and that the proper function of its themes lay in critical negativity, that is their function to demystify their opposite numbers. The examination of the anti-Utopia, then, of the fear of Utopia, has led us to identify a fundamental source in the very form of utopia itself, in the formal necessity of Utopian closure'.

Taking example from Putrajaya's 'perfect' township development credentials is very different from Kuala Lumpur, the capital city for Malaysia. Whereas Foucault [4] posits, the development of Kuala Lumpur is not an anti-utopia but heterotopias - spaces of real world, chaotic, contradiction-laden, spaces within spaces - and few cities are more heterotopian than Kuala Lumpur. According to King [2]:

'Kuala Lumpur, one of the great multi-cultural cities of the world Chinese and Malay and Indian, (sic) variously super-imposed, intersecting, jumbled up, forever transgressive of any purist vision, brilliant and exciting.

In contrast to the development of Kuala Lumpur, the geography and location of the Federal Territory of Putrajaya is somewhat of a traditional notion of a utopian city - a space of order, harmony and perfection, and is built according to a series of comprehensive policies and guidelines on land use, and the provision of transportation, utilities, infrastructure, housing, public amenities, parks and gardens. Putrajaya, eschewing complexity and ambiguity, is a dream of the space of a new form of a nation. It presents Malaysians with a new experience where nature and technology come together to benefit the community. In achieving the 'utopian ideal', the planners of Putrajaya in 1993 adopted a concept termed as Intelligent Garden City. According to a KWP (Federal Territory Ministry) [5] 
Malaysia's Putrajaya is the first Intelligent Garden City with a sophisticated information network based on multimedia technologies report, 'Putrajaya will become a vital developmental catalyst due to the role it will assume as a model city - as the nerve centre of the nation and an ideal place in which to live, work, conduct business and engage in sports and recreational activities'.

Putrajaya employs a Garden City concept which is created with the guidance of three simple ideologies: 'Man and his Creator; Man and man; and Man and nature' (Lilian et al. [6]). The layout of Putrajaya is constructed with three different features - a formal axis punctuated with nodal features; structuring of the Core Area into identifiable precincts; and variety of informal and formal activity areas. This includes thirty eight percent $(38 \%)$ of the land earmarked as green areas, the reforestation and enhancement of the natural landscape; promoting local flora as a Malaysian landscape identity; and creating a network of open spaces. The design of Putrajaya has also adopted an urban form that is designed to suit topography, local climate and cultural norms; the creation of an interesting cityscape; the optimisation of scenic panoramic views and spatial experiences; and finally the incorporation of intelligent buildings and infrastructural features. As Issace John [1] pointed out, 'In line with the Garden City concept, a large proportion of the city area is designated as parks and open space ranging from metropolitan parks to local neighbourhood playgrounds. Reinforcing these provisions are urban features such as landmarks, squares, plazas and bridges that form part of the cityscape, providing a wide range of spatial experiences that further enhance the spatial quality of the city'.

The urban design of Putrajaya for example, is an unquestionable effort in representing specific 'wished for' forms and images of the socio-cultural identity of the country; a concerted effort and a monumental task requiring the input of various groups of people with diverse disciplines. According to Vale and Dovey [7], 'Cities inevitably convey messages about the societies that produced them and are in turn reproduced by them, in their image, as it were. This is even more so in the case of capital cities'. Putrajaya's design in this instance is guided by the Garden City concept and aiming to achieve a strong image for the city, effort towards 'good urban design and landscape planning is achieved through the use of the Detailed Urban Design guidelines' (DUD) (Issace John [1]).

The DUD guidelines are prepared at the precinct level. It outlines the general character and ambience of each particular development plot but at the same time, tying its design to the surrounding development in 'parcels' and 'precinct' as a whole. By this, the DUD promotes an urban fabric and language through the composition of its many elements, combining them to reflect a unique sense of place and character. The DUD guideline achieves this by focusing on elemental guiding principles such as urban structure, urban form and urban character. It is aimed towards an urban form that projects visual unity and coherence, affording a distinctive image for the city and a quality spatial experience for citizens and visitors alike. The DUD guidelines have been used to create identifiable urban spaces and corridors such as the Putrajaya Boulevard and the Dataran Putrajaya where the National Day Merdeka Parade is held. 
As an extension to the effort of creating an image and character for the city, the Putrajaya Lighting Master Plan has also been formulated to establish the visual and practical architectural lighting criteria to ensure the night-time ambience of Putrajaya is attractive and appropriate of a city of its status and function. Putrajaya at first reading is a city that is inevitably a pinnacle of Malaysian political programming. Its unique 'ceremonial' space and the symbolism of the architecture of Putrajaya have drawn upon diverse influences resulting in buildings that are uniquely 'Malaysian-Islamic' in character and universal in outlook (Mohd and Noor [8]). As the new administrative centre of Malaysia, Putrajaya symbolises the Malaysian national identity in architecture. According to Ali, while Malay and Islamic design idioms dominate the architecture of Putrajaya, it also incorporates classical and contemporary elements that reflect the universal outlook of the Malaysian psyche. The city design also reinforces the distancing of the executive and bureaucracy from the legislature, which is, a profoundly political action. This is based on the master plan of Putrajaya where the palatial grandeur of the Prime Minister's Office spearheads the city overlooking the boulevard and all the buildings alongside the axis (see figure 1). The placing of the Prime Minister's Office at the pinnacle of the ceremonial space of the city is officially referred to as an administrative centre rather than capital.

The grandeur is then extended to the boulevard and the waterfront (see figure 2.), which is comparable to and speaks the same architectural language as most administrative cities like Canberra, Washington D.C., Brasilia and Versailles. According to interview participant Abdullah [9], the Putrajaya Boulevard represents the continuum of Malaysia's history since Merdeka. Commencing at Dataran Putra (Putra Plaza), it links the aspirations and
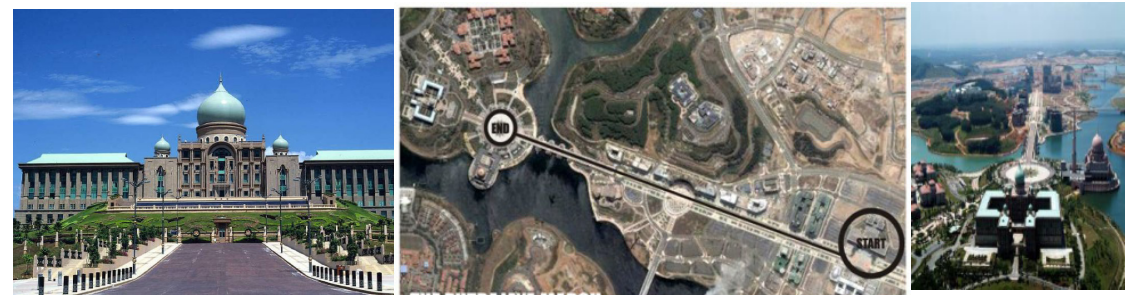

Figure 1: $\quad$ The prime minister's office (left), axis (middle and right).
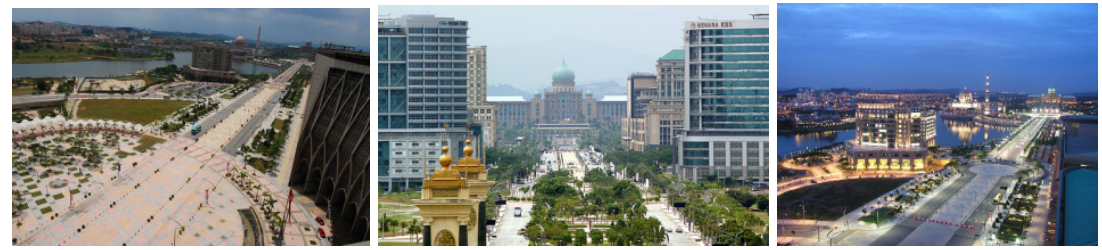

Figure 2: $\quad$ View of Putrajaya Boulevard. 
objectives involved in building a visionary nation. The Dataran shows the linear progression from the past to the present, and to Malaysia's future.

The Dataran or Plazas serve as boundaries or as connections between areas of the city and are the 'gateways' that stand symbolically as ceremonial axes framed by the buildings. The skyline of buildings and architectural features along the entire length of the boulevard are formed and punctuated in terms of the various heights of the buildings and the massing at each Dataran. The boulevard itself is an uninterrupted single entity and forms a coherent formal ceremonial setting, which includes sculptures, shelters and lighted lanterns. Characterising the design scheme was an almost relentless formality of major, minor and radiating axes, not to mention the symmetrical federal governmental building complexes. The design heightens the sense of order, and 'manifests a symbolic expression of the executive arm of the government and the bureaucracy' (King [2]).

Political practices can be seen, in large measure, as surface expressions of a deeper cultural substratum - beliefs, values and practices, more broadly. The above points are reasonably non-controversial observations of political messages, conveyed in the design of the city. Further analysis of Putrajaya, reveals its settings representing a 'Cultural Programme' simply because the design of Putrajaya itself raises profound questions of identity and selfredefinition. King [2] states: 'Issues of identify and self imagery emerge in the matter of the city's imagery - style, but also subjects of that style'.

The imagery of Putrajaya is not unexpected, as its' domes, coloured tiles and polished stones, together with the axial pieces are found in the formalities of major mosque designs in Malaysian cities like Kuala Lumpur and Shah Alam the state capital of Selangor. At one level, the design of Putrajaya is simply at the end of a long line of formalist, domed, arched and arcaded architecture adopted notably for mosques. At another level, the design has crossed over its original intention to include the design of offices, shopping malls, resort hotels and public art/ landscapes. The line of design can certainly be traced to the Bangunan Sultan Abdul Samad, built in 1897 (see figure 3) to house an earlier Malayan administration of the Federated Malays States. According to King [2]:

'It is clear that the building is styled in the British Raj design, and so the line of descent can be readily be traced to Victorian England-India and its representation of an earlier Mogul Islamic tradition' (sic).

Such colonial lineage is now scarcely acceptable politically, so with the master plan design of Putrajaya, there has been a transformation of the tradition. The design was stripped of its lineage complexity of the colonial Mogul and Moorish architecture. Instead a geometric simplification, both in its form (domes, arcades, etc.) and its surface treatments is flatter, simply geometric, thus, intentional. Putra Mosque and the Palace of Justice, for example, are certainly the most finely elaborate buildings in the city; claiming their source from the "Islamic Persian Safavid period" (Kervin [10]). While the bridges are fanciful and use high-technology engineering, the most important bridge of all is 'Putra 

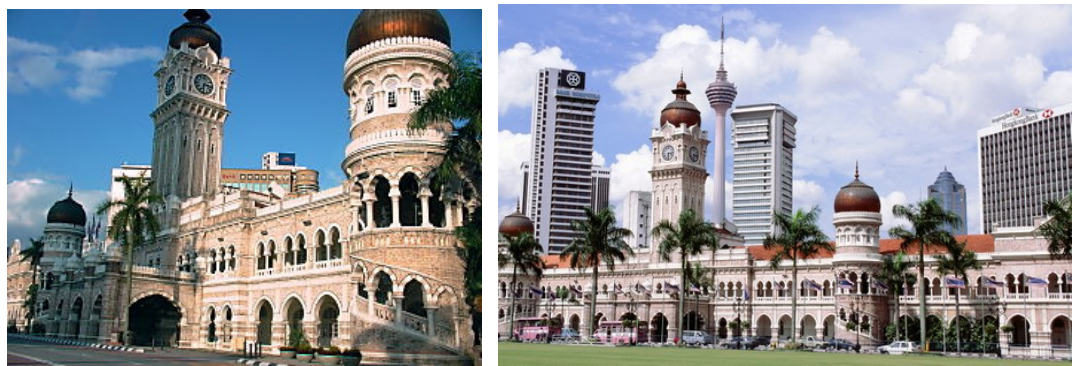

Figure 3: Bangunan Sultan Abdul Samad.

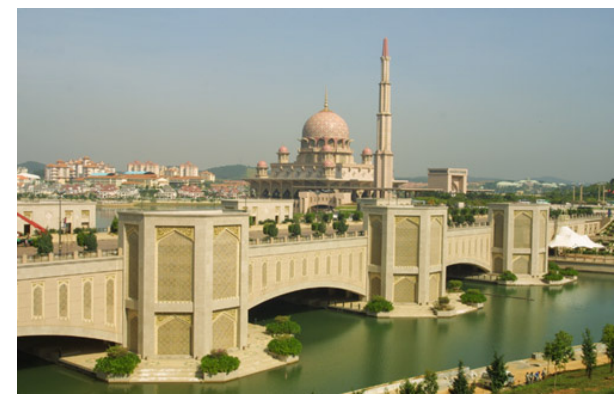

Figure 4: $\quad$ Putra Bridge, Putrajaya.

Bridge' which is 'designed and constructed in accordance with Islamic architectural principles to resemble the Khaju Bridge in Isfahan, Iran' ( $\mathrm{PjH}[11])$ (see figure 4).

It is quite certain that the turn to Middle Eastern Islamic tradition is a desire to have a modern city but not design based on a Western template. Nevertheless, there are other dimensions to the identification with the Middle East. It is the global revival of the Islamic world. Although Malaysia is indeed modern and sometimes ambivalently sympathetic to the West, Malaysia sees itself decidedly as a modern Islamic economic power bloc to stand against Europe, America and Australia. King [2] states:

'While Malaysia might be the richest state in the region (excluding minuscule Singapore and Brunei), it is also relatively small, so to have leverage through its own region (via ASEAN), and through a more globalist pan-Islamic bloc, will give it the international status to which it feels entitled. So the imaging of Putrajaya fits a grander agenda'

\section{Role of public art: whose public art?}

Weber [12], states that 'public art, whether abstract or figurative, asserts moral claims to public space, claims concerning the history, identity, and possible 
future of the surrounding area'. Public art design plays a key role in all forms of development, generating a sense of regional identity and pride. Successful public art is work that resonates with the site and context, creating an opportunity for the range of people using the site to engage with. In terms of added values, public art brings benefits to both the community and the environment. First, the employment of public art in Malaysia and the local authority is seen to contribute towards critical evaluation of art in public and social space values. This according to Bach [13]

"Public art can express civic values, enhance the environment, transform a landscape, heighten our awareness, or question our assumptions. Placed in a public site, this art is therefore for everyone, a form of collective community expression."

The ability of public art to meet the needs of social objectives for an inclusive society also largely depends on the quality of the built environment. In public places, there are many forms of art that enhance the space and give it character. In the case of major cities in Malaysia and an example of Putrajaya, public art helps break the rigidity of building complexes and the formal outlook of its urban-scape. In general it improves the physical environment to benefit the residents and visitors. It also helps to humanise public spaces and create meaningful places where people feel comfortable and relaxed. According to Andy from TR Hamzah and Yeang [14], 'the purpose of public sculpture in Putrajaya is to create a focal point for people to come and appreciate this artwork set against the development of Putrajaya...or its function is to address the purpose of the space...for example the sculpture located at the main entrance signify the formality of the business...It is also there to mark the city development'. Besides adding to people's appreciation of a particular place as well as aiding orientation, public art of all kinds can be found in almost any city either representing a historic figure or expressing a style, thought or culture. Andy [14] also states:'...for example the Millennium monument by Ken Yeang, (sic)...Generally it is there to create interest, to create the right atmosphere. The sculpture here (sic) is use to educate the public on the history of the country'

The Federal Territory of Kuala Lumpur or DBKL (Municipal) Landscapes department states: 'Murals are found on the sides of buildings, sometimes advertising a product or event, or expressing something of cultural, historical, or visual importance. Other forms of public art like fountains celebrate the reflections and coolness of water and add white noise, drowning out the sounds of traffic' (DBKL [15]). In Malaysia, water element is part of the public art which is important in a hot and humid climate like Malaysia's. This encourages 'liveability' in the community, which in turn promotes the quality of life (see figure 5).

In Malaysia, the employment of public art is believed to help create safer environment. With public art, the areas are better managed, well lit, streets are wider (to accommodate visitors and residents) - all these encourage visitors and the local community to use the streets at night, increasing natural surveillance. In 


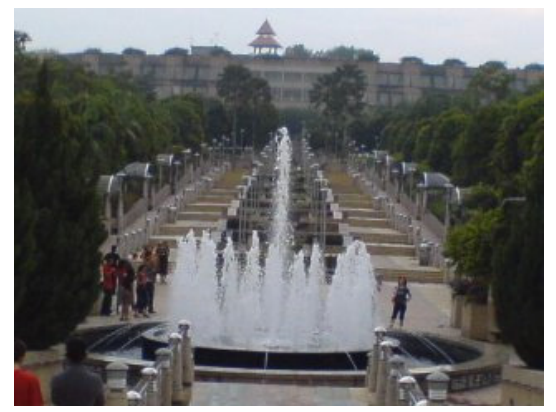

Figure 5: $\quad$ Sculptures and water fountain in Malawati Hill, Putrajaya.

this instance fear of possible crime is lessened. It also helps decrease vandalism and increase community pride and concern for the local environment, which allow its communities to directly influence the identity of the area, encouraging greater ownership of a development or scheme. On a larger scale, public art in Malaysian cities provides a community focus where the artwork in the public spaces creates a potential venue for social events. These events can provide interactions and encourage cross-community and cross-cultural ties. It can also have a very positive effect on the urban environment, drawing the community together - bringing financial, social and environmental benefits, whilst broadening the cultural nature, character and identity of the area. This is clearly evident in Putrajaya. Abdullah [9],'In Putrajaya, the residential developments were developed on the Kampung concept where no fences were allowed thus creating a village environment...it will provide and encourage interactions between the neighbours'

While good urban design and architecture affirm social values and bring coherence and order to the built environment for the benefit of the public; commissioned sculptures and integrated artworks located throughout the city in parks, along roadways, in public buildings and in other public places help enhance urban spaces and create a sense of place. According to Sucher [16]:

'The urban environment can become personalised with art by demonstrating a particular style, activity, or culture. Art creates a sense of place, it reflects social theory about the place, and displays a style that is attributed to the space. Art is often used in public places to give it character, to make a space interesting, or to simply beautify it. People remember a place because of the artwork that exists in the space - the art acts as a symbol of the place'.

The employment of public art in Putrajaya is a prime example of a direct response to its settings and a reflection of Malaysia's political and cultural programme, which presents a typical celebration of ornamental display intertwined with a series of administrative and political considerations. As mentioned above, Putrajaya's development was inspired by the idea of remaking Malaysia into a modern Islamic economic power. Abdullah [9] states 
'...religion plays a big role in the decision making especially with the local authority when they want to put public art. Firstly because they use public money, where the majority of the public is Malay Muslim and they are accountable when using this funding.

Public art is employed to display between the actual and wished for identity, a vision of an ideal urban space. Public art and monuments were incorporated into Putrajaya's built environment where appropriate to further enhance, establish and create a unique identity legitimising the political and cultural atmosphere. According to Pearson [17]:

Public art is now related to cultural identity... it became 'directly political in the broader sense, since [state involvement] is wrapped up in values, decisions, attitudes and assumptions concerning people's lives'

The issue of cultural and political values both define and mediates by its spatial location, and as such, is part of a social dynamics in which 'the processes through which a person defines him / herself in a society are not restricted to making distinctions between oneself and significant others, but extends with no less importance to objects and things, and the very spaces and places in which they are found' (Proshansky et al. [18]).

To help understand this, it is important to look at the distribution of public art in Putrajaya. Almost eighteen public sculptures were located and found within a radius of two kilometres from the central core zone (Precinct 1-5), which is also the administrative and financial district. Most public artwork in the administrative and financial areas carry a style to coincide with the visual language of Putrajaya's built environment. It is claimed to be Malaysian (reminiscent of Malay vernacular architecture) and an adaptation of Middle Eastern Islamic principles. Because of the Malay-Islamic style, spatial representation (the architecture and built environment) has explicitly used peculiar form of abstract geometry (an anti-anthropomorphic tradition in Islamic decorations); which also physically influenced the public art attributes in these areas. While the usage of geometrical form helps enforce an Islamic identity, Malay carvings and Malay art style, on the other hand is used to help enforce the Malay cultural tradition. Residential, recreational and trade areas have very little public art, which is often attributed to the value of the space (or rather the lack of). According to Mohd and Noor [8] "the "Peripheral Precincts" plan are base on the neighbourhood planning concept to accommodate a mixture of residential areas, local commercial activities and public amenities and it does have sculptures which symbolically commemorate Putrajaya's 'Garden City' design concept.

Mohd suggests that public art in the "Peripheral Precincts" does not hold the same values as the one in the "Core Areas". If the public art in the "Core Areas' are site-specific and politically and culturally motivated; the only purpose of public art in the peripheral areas is to enhance the aesthetic values of the settings. Hence the designs in the peripheral areas are more liberal and utilise a more modern approach. Public art within the core areas, illustrating political and 
cultural values, are site-specific - symbolic of the political history of Malaysia. This is because the public realm was perceived by the ruling politicians or dictated by how they thought of the city, by way of its public space and objects. According to King [2]:

'...the use of public art in Putrajaya is to help enforce a political and cultural imagery and it is the surface expression of a deeper cultural layer conveyed in the design of the city'

The impact of public art goes beyond value of social and identity. Public art in Putrajaya also contributes towards economic benefits. As Madden [19] states, "The phrase the "economic benefits of the arts" has gained currency in arts sectors around the world, largely as a result of a new economic rationalism in public policy'.

As with all areas of public policy, arts and cultural policies have come under the scrutiny of economics. Putrajaya has created a high quality public environment, which has significant impact on the economic life of the urban centre to attract investment. The presence of good parks, squares, public art and public spaces becomes a vital business and marketing tool - investors are attracted to locations that offer well designed, well managed public places and these in turn attract customers, employees and services. Public art is also used for tourism in Putrajaya. For example, the Mercutanda monument, Perdana Boulevard sculpture and Millennium monument in Precinct 2 are examples of public art used to attract visitors to visit Putrajaya. There are seven main dedicated attractions for tourism (see figure 6).

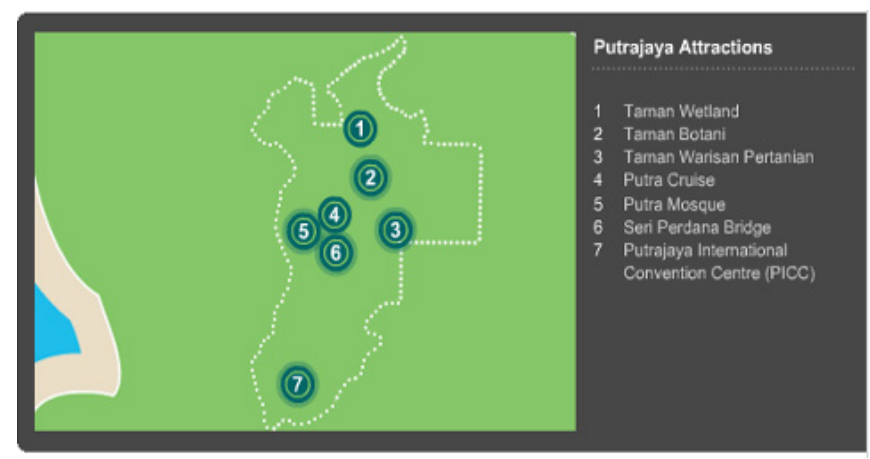

Figure 6: Putrajaya attractions: (courtesy of Putrajaya Corporation).

Tourism in Putrajaya offers visitors an introduction into Malaysian cultural constructs where the mode of representation is instrumental in determining the progress of integration. While, according to Putrajaya Corporation (PJC), a good public landscape offers very clear benefits to the local economy in terms of stimulating increased house prices, since house buyers are willing to pay to be near green space. Apart from that, PJC [20] states, 'The employment of public 
art will amplify the aesthetic value of the public spaces (sic) and encourages families and visitors to use such facilities'.

PJC believes that the employment of public art can only mean a good quality public place and positive environments; which will attract more people to the area. But public art values are an easy target for criticism. While the benefits of public art to the community (streetscape, street furniture, a painting or a sculpture) are not the kind that shows up on the balance sheet or lead to tax rebates or goes well beyond cash registers and tax revenue, it has value, both in economic and social terms. Where there is art, there is a visible difference of an active cultural community - people engaging with the environment, growth of social interactions between different cultural backgrounds, celebration of the built environment increase in the use of open spaces and reduced vandalism by encouraging a sense of pride and ownership.

The traditional reasoning is that the arts produce cultural benefits that spill over onto the general public and help to educate the public with the value of the arts. It may also culturally enrich the community and bring external prestige to their community, encourage greater cultural tolerance and diversity when the majority of the groups/community are exposed to other cultures and taste through the arts.

\section{Conclusion}

Apart from political and cultural representation, Putrajaya also represents the 're-making of Malaysia'. While Malaysia experienced a history of racial tension, the separation of functions and of spheres, Malay political hegemony but Chinese economic dominance; and quality of spatial qualities that are significantly shared by the three major ethnic groups, the diversity is not replicated in Putrajaya. Putrajaya is a civil service town and the civil servant is overwhelmingly Malay and Muslim. On one level, Putrajaya is part of an ongoing endeavour to re-establish Malay and Islamic pride and self-respect.

While Putrajaya, in a sense, is trying to escape from the diversity of the city, it is notable that the imported 'style' is not that of the Kampungs (Malay village), Masjids (mosques) and Istanas (Palaces) of the Malay tradition. Rather it is of an 'imagined' source. Putrajaya is both in way, colonised by images and styles essentially Middle-Eastern and the colonising of a Malay reassertion against 'an urbanism and urbanity that is essentially and simultaneously Chinese-Malaysian and cosmopolitan' (King [2]).

The fact that public art has received much attention is simply because it has been engineered to help boost Malaysia economic prowess by reflecting the country as innovative, safe and stable for investment. This portrayal of economic stability encourages positive economic growth while sustaining the traditional and cultural values. This is achieved through uninhibited imagination and the confluence of artistry, science and aesthetics for the continuum of economic and socio-political sustainable liveability. 


\section{References}

[1] Issace John, Jebasingam (2005) 'Creating the Essence of Cities: The Planning and Development of Malaysia's New Federal Administrative Capital, Putrajaya', Discussion Paper.

[2] King, Ross (2005) Re-writing the City: Putrajaya as Representation Journal of Urban Design Vol12 No.1 February 2007 pp. 117-138.

[3] Jameson, Fredric (2005) Archaeologies of The Future (Poetics of Social Forms) Verso.

[4] Foucault, Michel. "Nietzsche, Genealogy, History." The Foucault Reader. Ed. Paul Rabinow. New York: Pantheon, 1984. 76-100.

[5] Malaysia Federal Government Document (2007) Ministry of Multimedia and Communication Malaysia.

[6] Lilian T.Y.C.1, Ho C.S. and Ismail S. (2002) Some Planning Consideration Garden City Concept towards Achieving Sustainable Development Proceedings of the Regional Symposium on Environment and Natural Resources (Vol. 1) p.2.

[7] Vale, L.J., Dovey 1992. Architecture, Power, and National Identity. New Haven: Yale University Press.

[8] Mohd Ali, Noor Azizi (2006:97) Paper 6: PUTRAJAYA and The French Connection Universiti Teknologi Malaysia pp 97-106.

[9] Abdullah, Jamalunlaili August 2006 Interview Participant.

[10] Kervin, Chong (2006) 'Mosque Week- Masjid Putra' [http://kervinphotos.blogspot.com] accessed 21 March 2008.

[11] $\mathrm{PjH}$ - Putrajaya Holdings Document (2005) Putrajaya's Boulevard and Waterfront Core Administration Center Putrajaya Holdings.

[12] Weber, John Pitman (2003) Politics and Practice of Community Public Art: Whose Murals Get Saved? The Getty Conservation Institute.

[13] Bach, Penny Balkin (1992) Public Art in Philadelphia Philadelphia: Temple University Press.

[14] Andy of TR Hamzah and Yeang, 24 August 2006 Interview Participant.

[15] DBKL - Dewan Bandaraya Kuala Lumpur (2006) Public Sculpture in Malaysia: A Case Study of Putrajaya Interview participant.

[16] Sucher, David (1995) Reclaiming the City: Mix Use Development Andy Couplan (ed) Taylor and Francis.

[17] Pearson, N (1982) 'Cultural and Identity' in Urban Cultural Strategies and Urban Regeneration: A Case Study and Critique Basset, K (1993) (ed) Environment and Planning Paper $1993 \mathrm{Vol}$ 25(2).

[18] Proshansky, H.M., Fabian, A.K., and Kaminoff, R. (1983), Place-Identity: Physical World Socialization of the Self, Journal of Environmental Psychology, 3.

[19] Madden, Christopher (1998) Economic Benefits of Public Art: Discussion Paper, New Zealand Art Council.

[20] PJC - Putrajaya Corporation (2006) Public Sculpture in Malaysia: A Case Study of Putrajaya Interview participant. 